\title{
Activated Carbon Prepared from Orange Peels Coated with Titanium Oxide Nanoparticles: Characterization and Applications in the Decomposition of $\mathrm{NO}_{x}$
}

\author{
LILIANA GIRALDO ${ }^{1}$ and JUAN CARLOS MORENO-PIRAJAN²* \\ 'Universidad Nacional de Colombia, Facultad de Ciencias, Departamento de Química, \\ Carrera 30 No 43-00, Bogotá, Cundinamarca, 001/Colombia \\ ${ }^{2 *}$ Universidad de los Andes, Facultad de Ciencias, Departamento de Química, \\ Grupo de Investigación en Sólidos Porosos y Calorimetría, \\ Carrera 1 No 18 A 10, Bogotá, Cundinamarca, 001/Colombia \\ *Corresponding author: E-mail: jumoreno@uniandes.edu.co \\ http://dx.doi.org/10.13005/ojc/300207
}

(Received: February 28, 2014; Accepted: March 30, 2014)

\begin{abstract}
In this work, we report the degradation of $\mathrm{NO}_{\mathrm{x}}$ using two catalysts prepared by coating activated carbon from orange peels with $\mathrm{TiO}_{2}$. This study compared the performance of $\mathrm{TiO}_{2}-$ coated catalysts prepared by CVD $\left(\mathrm{AC} 1 / \mathrm{TiO}_{2}\right)$ and the sol-gel method $\left(\mathrm{AC} 2 / \mathrm{TiO}_{2}\right)$. The catalysts were characterized by $\mathrm{X}$-ray diffraction, BET surface area and TEM. The photocatalytic activity was measured by studying the degradation of $\mathrm{NO}_{x}$ in the vapor phase. The results show that the catalyst synthesized by the CVD method was more efficient in the decomposition of $\mathrm{NO}_{\mathrm{x}}$. TEM and XRD revealed the presence of a mixture of the anatase and rutile phases, which favors the $\mathrm{NO}_{\mathrm{x}}$ decomposition process. Nitrogen isotherms showed that coating the nanoparticles with titanium oxide did not significantly change the surface area of the original activated carbon.
\end{abstract}

Key words: photocatalysis, activated carbon, isotherms, $\mathrm{NO}_{x}$ degradation

\section{INTRODUCTION}

Research on pollutants and their sources that are emitted to the environment are very varied. The scientists must propose solutions to this problematic, which is an topic that today is a problem of great importance to society, problem that requires researchers with new ideas for propose the realization of solutions to the pollution control and ensure that ecosystems reach its natural balance. The research in the laboratories of the Universities have the fundamental idea that later can be applied to small-scale and large-scale later. Thus, it may in a short period of time, that the large part of the pollutants which are now environmentally hazardous, begin to decrease. Automotive traffic exhaust contains many hazardous gaseous pollutants, such as nitrogen oxides $\left(\mathrm{NO}_{x}\right)$, which 
affect the health of people living in urban areas ${ }^{1,2}$. Reducing $\mathrm{NO}_{x}$ concentrations is therefore important in order to promote sustainable development ${ }^{3,4}$. The oxides of nitrogen, $\mathrm{NO}$ and $\mathrm{NO}_{2}\left(\mathrm{NO}_{x}\right)$, have a variety of negative impacts on human and environmental health, ranging from serving as key precursors of the respiratory irritant ozone to forming nitric acid, which is a key component of acid rain. Hence, it is of great interest to develop approaches that irreversibly remove $\mathrm{NO}_{\mathrm{x}}$ from the atmosphere.

Industrial development in the past five decades has brought the planet to a very worrying collapse from the environmental point of view because of the uncontrolled increase in the use of fossil fuels as the main energy source; the average global temperature will increase and thereby alter the ecosystem. In particular, the excess emission of gases from the internal combustion engine and industry has become one of the major causes of environmental pollution, where gases such as $\mathrm{CO}_{2}$, $\mathrm{CO}$, hydrocarbons, $\mathrm{SO}_{2}$, and $\mathrm{NO}_{\mathrm{x}}$ generate volatile organic compounds (VOC) and particulate matter. These compounds have led to the greenhouse effect, acid rain, photochemical smog, stratospheric ozone depletion, and the aforementioned global warming. These events impose considerable negative effects on human and animal health due to the high toxicity of the compounds mentioned ${ }^{1,2}$. Nitrogen compounds such as nitrogen oxides $\left(\mathrm{NO}_{\mathrm{x}}\right)$ and sulfur $\left(\mathrm{SO}_{\mathrm{x}}\right)$, which are considered the most toxic gases, are emitted into the atmosphere during the combustion of fossil fuels. To reduce these emissions, several studies have used porous materials such as mesoporous materials, modified mesoporous materials, aluminas, silicon compounds, compounds derived from coal as both chemically and physically activated powders, granular materials, and fabrics modified with $\mathrm{TiO}_{2}^{5,6}$. Nitrogen oxide $\left(\mathrm{NO}_{x}\right)$ emissions into the atmosphere have a direct impact on the global environment and human health through ozone depletion, photochemical smog and acid deposition ${ }^{1-3}$. The wet scrubbing method is an efûcient and economical way to remove soluble pollutants ${ }^{3}$. In order to remove $\mathrm{NO}_{x}$ by the wet scrubbing method, it is necessary to oxidize nitric oxide (NO) into the more soluble nitrogen dioxide $\left(\mathrm{NO}_{2}\right)$ or dinitrogen pentoxide $\left(\mathrm{N}_{2} \mathrm{O}_{5}\right)$ in either the gas or liquid phase ${ }^{4-}$ 9. However, it is very difûcult to oxidize dilute NO without the addition of strong oxidants such as methanol, ozone and hydrogen peroxide ${ }^{5-10}$.

For several decades, it has been known that heterogeneous photocatalysis represents an emerging environmental control option for the efficient removal of chemical pollutants, as it can be applied to water and air purification. This process involves a nano-solid semiconductor catalyst, usually titanium dioxide $\left(\mathrm{TiO}_{2}\right)$, which is activated with ultraviolet light at the appropriate wavelength. For various reasons, titanium dioxide in the anatase form has been the preferred choice due to its strong oxidizing power under UV irradiation, its chemical stability and the absence of toxicity ${ }^{11}$. These reactions are very attractive for treating pollution because: (1) in the vast majority of cases pollutants are transformed into innocuous products ${ }^{11,12}$ and (2) the process has very low selectivity, thus permitting the treatment of a wide range of contaminants. Nowadays, smog is still problematic. Researchers have dedicated their time to studying the dynamics of the photocatalysis of nitrogen oxides. While some have focused on $\mathrm{NO}_{x}$ control methodology by the reduction to $\mathrm{NO}_{x}$ to $\mathrm{N}_{2}{ }^{11,13}$, another approach is to oxidize $\mathrm{NO}$ to $\mathrm{NO}_{2}$ and $\mathrm{HNO}_{3}$ along the general direction of nitrogen fixation. Photocatalytic oxidation (PCO) of $\mathrm{NO}_{x}$ offers the following important advantages: (1) no extra reactants are required and (2) $\mathrm{NO}_{x}$ is recycled or recovered as nitric acid, a potential raw material for fertilizers. The scientific literature has reported a number of interesting publications on the treatment of $\mathrm{NO}_{x}$ with $\mathrm{TiO}_{2}$, so photodegradation for this compound. There are also interesting publications in which kinetic studies have been carried out on the possible mechanisms of the $\mathrm{TiO}_{2}$ photocatalytic reaction with $\mathrm{NOx}^{11,17}$. Several researchers ${ }^{11,14}$ have discovered that, during the photodegradation process, interaction with certain pollutant molecules or their intermediates can cause the $\mathrm{TiO}_{2}$ powder to coagulate, thereby reducing the amount of UV radiation able to reach $\mathrm{TiO}_{2}$ active centers (due to a reduction in surface area), thus reducing its catalytic effectiveness ${ }^{11}$. In order to overcome this coagulation problem, some researchers have used different materials as a support for the titania photocatalyst. Various substrates have been used as a catalyst support for the photocatalytic degradation of polluted water. From a survey of the literature, we can 
establish certain criteria for selecting an optimal catalyst support. The supporting material should be transparent or at least allow some UV radiation to pass through it and be chemically inert or nonreactive to pollutant molecules, its intermediates and the surrounding aqueous system. The supporting material should sufficiently bond either via physically or chemically to $\mathrm{TiO}_{2}$ without reducing the reactivity of titania. The supporting material should have a high surface area and a strong adsorption affinity for the pollutants (organic or inorganic compounds) to be degraded. This criterion reduces or eliminates the intermediates produced during the photocatalytic degradation while further increasing mass transfer rates and processes for efficient photodegradation. The supporting material should also allow for fast and easy photocatalyst recovery and re-use with or without regeneration. Based on these criteria, activated carbon (AC) has been extensively researched and used as a support material for $\mathrm{TiO}_{2}{ }^{11,16,17}$.

Besides being used as a catalyst support, some researchers have used $\mathrm{TiO}_{2}$ and $\mathrm{AC}$ mixtures to treat pollutants. The literature reports some benefits of $A C$ supports in the preparation of titania photocatalysts. A greater AC content in the supported photocatalyst translates to a higher surface area for the supported photocatalyst and higher adsorption capacity. The pore volume of AC is directly proportionate to the amount of $A C$ in the catalyst ${ }^{11}$, indicating that $\mathrm{TiO}_{2}$ particles actually agglomerate on the carbon surface without being adsorbed into the carbon pores. However, pore trapping may still occur to a small extent. An AC content less than $13 \%$ of the supported photocatalyst weight will create a homogeneous distribution of $\mathrm{TiO}_{2}$ on the surface ${ }^{11,18}$. A heterogeneous distribution will occur if the percentage of the carbon is greater than $13 \%$, causing both the $\mathrm{AC}$ and $\mathrm{TiO}_{2}$ particles to form conglomerates. Organic compounds are hydrophobic, whereas $\mathrm{TiO}_{2}$ particles, when exposed to UV radiation, are hydrophilic. Using AC as a photocatalyst support will help bring the pollutant molecules closer to the $\mathrm{TiO}_{2}$ active site (to come in contact with hydroxyl radicals) for an efficient and effective photodegradation process (synergistic effect). AC can generate new adsorption centers to favor approaching pollutant molecules. Using activated carbon as a support will also enable secondary degradation of intermediates to take place in situ, further enhancing the effectiveness of the photocatalyst. Moreover, using $A C$ as a support allows for fast and easy photocatalyst recovery and provides ample room for catalyst regeneration using various techniques ${ }^{11-16,18}$. This is because the supported photocatalyst can be made into a granular form, providing an easy filtering option for recovery from the slurry ${ }^{11}$. Besides possessing all the criteria and benefits of a catalyst support as established in the literature survey, $\mathrm{AC}$ is non-polar, non-reactive, highly adsorptive and cheap to manufacture or purchase.

The purpose of the present work was to prepare AC from orange peel under specific conditions in the lab and to deposit on its surface nanoparticles of $\mathrm{TiO}_{2}$ using two different techniques, with the purpose of comparing its performance in the decomposition efficiency of $\mathrm{NO}_{x}$.

\section{Methods and Experimental Materials}

AC was prepared as reported in our previously published work ${ }^{19}$. Prior to use, the orange peel was repeatedly washed with distilled water in order to remove dust and other inorganic impurities, then oven-dried for $24 \mathrm{~h}$ at $393 \mathrm{~K}$ to reduce the moisture content and milled to a size $<1 \mathrm{~mm}$. Peels from Colombian oranges were impregnated with an aqueous solution of $\mathrm{KOH}$ following a variant of the incipient wetness method; similar cases have been described in the literature ${ }^{19-27}$. This consists of adding dropwise (while stirring the solid, to facilitate homogeneous absorption of the liquid) a specific amount of the aqueous solution $\left(2.0 \mathrm{~mL} \mathrm{~g} \mathrm{~g}^{\prime 1}\right.$ orange peel) necessary to produce swelling until incipient wetness. In this study, the concentration of $\mathrm{KOH}$ in the aqueous solution was $160 \mathrm{wt} \%$, which was expressed as the impregnation ratio $\left(X_{p}, w t . \%\right)$, defined as ( $\mathrm{g} \mathrm{KOH}$ per $\mathrm{g}$ orange peel) $\times 100$. After impregnation, the samples were dried for $8 \mathrm{~h}$ at $383 \mathrm{~K}$ in air. Pyrolysis treatment (activation) was carried out in a vertical tubular reactor made of quartz in a Carbolite ${ }^{\mathrm{TM}}$ furnace, in all cases using $25 \mathrm{~g}$ of the impregnated and dried material. All treatments were performed at a constant heating rate of $10 \mathrm{~K} \mathrm{~min}^{-1}$ and with an argon (99.999\% pure) 
flow of 30 STP $\mathrm{cm}^{3} \cdot \mathrm{min}^{\text {"11 }}$, which was maintained during heating and cooling. An activation temperature of $823 \mathrm{~K}$ and a soaking time of $4 \mathrm{~h}$ were used. After cooling the solid pyrolysis residue to room temperature, it was washed with Milli-Q distilled water until the conductivity of the washing liquid was lowered to $<51 / 4 \mathrm{~S} \mathrm{~cm}^{\prime \prime}$ (measured using a pH/conductivity meter; HP, model MARK 602). The resulting ACs was dried at $383 \mathrm{~K}$ for $24 \mathrm{~h}$ in a vacuum furnace.

\section{Preparation of the photocatalyst samples Chemical vapor deposition (CVD) method}

This experiment was based on the work of Ding et al..$^{28}$ and Amjad et al. ${ }^{29}$. We have designed and built a system based on publications by other authors by making some adjustments to improve the variability of the equipment.

The reactor for CVD synthesis consisted of a quartz tube that was made of this material due to its chemical inertia during the evaporation of the reagent, which was inserted into a tubular furnace in order to obtain the desired coating temperature. As the particles of the support were quite small and as there was no means to support them, we designed and adapted a porous glass plate for the final part of the reactor that holds the activated carbon during the reaction and promoting the free passage of vapors. Seven milliliters of titanium tetra isopropoxide (TTIP) were placed in flask (a) of the reactor, while another container (b) was kept empty and immersed in an ice bath. The containers (a) and (b) were heated using two adjacent boiling water baths, which were heated before placing flasks (a) and (b), and kept under an inert atmosphere of nitrogen gas flowing through the system at a $1.7 \mathrm{~L} / \mathrm{min}$. This flow rate was sufficient to cause continuous movement of the particles inside the second flask to ensure homogeneity. When all the TTIP was consumed, water baths were switched off and the nitrogen flow was kept on until the system reached room temperature. The sample was then washed three times with distilled water to remove any suspended undeposited titanium hydroxide. The sample was then dried at $150^{\circ} \mathrm{C}$ overnight, then calcined for $3 \mathrm{~h}$ at $600^{\circ} \mathrm{C}$ to produce the anatase form of titanium dioxide. This procedure was followed has been reported in the literature ${ }^{28,29}$. This sample was designated $\mathrm{AC} 1 / \mathrm{TiO}_{2}$.

\section{Sol-gel impregnation method}

A nano-sized binary mixed oxide of $\mathrm{AC} /$ $\mathrm{TiO}_{2}$ was prepared by the sol-gel impregnation method $^{30}$. The synthetic procedure followed a typical sol-gel impregnation method to prepare a 1:1 molar composition of $\mathrm{AC} / \mathrm{Ti}$ mixed oxide. Under constant magnetic stirring, $7.6 \mathrm{~mL}$ of titanium tetraisopropoxide were added dropwise to a beaker containing $25 \mathrm{~mL}$ of isopropanol and $1.5 \mathrm{~mL} \mathrm{HCl}$, while the beaker was maintained at $0^{\circ} \mathrm{C}$. In another beaker, $8.2 \mathrm{mg}$ of AC were suspended in $25 \mathrm{~mL}$ of isopropanol and then was mixed dropwise into the first beaker with vigorous stirring. The mixture was then stirred at $25^{\circ} \mathrm{C}$ for $48 \mathrm{~h}$. The mixed sol was then sonicated in an ultrasonicator (up $200 \mathrm{~s}$, Hielscher, Germany) at room temperature for $30 \mathrm{~min}$. The sonicated sol was placed over a hotplate to remove the solvent. The resulting powder was calcined at a specific temperature and time. Nano-sized titanium dioxide was prepared using a similar approach.

Under constant magnetic stirring, $7.6 \mathrm{~mL}$ of titanium tetraisopropoxide were added dropwise to a beaker containing $25 \mathrm{~mL}$ of a solvent such as isopropanol and $1.5 \mathrm{~mL} \mathrm{HCl}$, an the temperature of beaker was kept at $0^{\circ} \mathrm{C}$ using a water and ice bath. The mixture was stirred at $25^{\circ} \mathrm{C}$ for $48 \mathrm{~h}$. The resulting sol was then sonicated for $30 \mathrm{~min}$ and then the solvent was removed over a hotplate with a rather slow stirring rate. The powder was calcined at the desired temperature and time. This simple was designated $\mathrm{AC} 2 / \mathrm{TiO}_{2}$.

\section{Textural characterization of activated carbons and the prepared catalysts}

To determine the surface area and pore structure of activated carbon samples, the nitrogen adsorption-desorption isotherms at $77 \mathrm{~K}$ were measured by an automated adsorption instrument (IQ2 Quantachrome, Boynton Beach, FL, USA) with $\pm 0.15 \%$ accuracy. The surface area, pore volume and pore size distribution were determined from nitrogen adsorption data using Quantachrome software. Adsorption data were obtained over the relative pressure, $\mathrm{P} / \mathrm{P}^{\circ}$, range from $10^{-5}$ to 1 . The sample was degassed at $250^{\circ} \mathrm{C}$ under a vacuum for $4 \mathrm{~h}$. The apparent surface area of nitrogen was calculated using the BET (Brunauer-Emmett-Teller) equation within the $0.01-0.3$ relative pressure range. The micropore volume was determined according 
to the DR (Dubinin-Radushkevich) method ${ }^{31-34}$. The amount of $\mathrm{N}_{2}$ adsorbed at relative pressures near unity $(\sim 0.99)$ corresponds to the total amount adsorbed in both micropores and mesopores; consequently, the subtraction of the micropore volume from the total amount will provide the volume of the mesopores. The pore size distribution was obtained by applying the density functional theory (DFT) method to the nitrogen adsorption isotherm using the software supplied by IQ2 ${ }^{31-32}$.

\section{Catalyst characterization}

X-ray powder diffraction (XRD)

XRD was performed using a Rigaku MiniFlex-II Xray diffractometer with $\mathrm{Cu} \mathrm{K} \alpha$ radiation $(\lambda=0.15418$ $\mathrm{nm})$. The sample was scanned from $20^{\circ}$ to $80^{\circ}\left(2_{s}\right)$ at a rate of $0.02 \% \mathrm{~min}$. The phases present in the catalyst samples were identified using the Joint Committee on Powder Diffraction Standard (JCPDS) powder data files. The XRD pattern and data were also analyzed using the Powder $X$ program $^{35-39}$. From these XRD patterns, the crystallite or grain size $\left(d_{x R D}\right)$ of the prepared powders was estimated using the Scherrer equation (Eq.1) as follows ${ }^{10,33-35}$ :

$$
\mathrm{d}_{\mathrm{XRD}}=\mathrm{K} \times \lambda / \beta \times \cos \theta
$$

where $\lambda, \theta$ and $\beta$ are the $\mathrm{X}$-ray wavelength, Bragg diffraction angle and the full width at halfmaximum (FWHM) of the diffraction peak, respectively. $\mathrm{K}$ is a constant normally equal to 0.94 and $\lambda=0.1540 \mathrm{~nm}$ (the wavelength of emission of the device).

\section{Transmission electron microscopy}

TEM measurements were performed on a Philips G20 Ultra-Twin transmission electron microscope equipped with a CCD camera. Operating at $300 \mathrm{kV}$, the microscope can achieve a point resolution of $0.14 \mathrm{~nm}$ and a line resolution of $0.1 \mathrm{~nm}$. Scale calibration was done on the Au (10 $0)$ planes. Both dry and wet deposition were performed with ethanol and water as the solvents. Powders were deposited on carbon coated copper grids.

Photocatalytic activity measurements: reactor and test

Fig. 1 depicts the continuous flow system used for $\mathrm{NO}_{x}$ degradation over $\mathrm{AC} 1 / \mathrm{TiO}_{2}$ and $\mathrm{AC} 2 /$ $\mathrm{TiO}_{2}$. A round Pyrex glass vessel $(\varphi \times \mathrm{H}, 15 \mathrm{~cm} \times 4$ $\mathrm{cm})$ was used as the photoreactor to assess the degradation of $\mathrm{NO}_{x}$, and a sample dish $(\varphi 7 \mathrm{~cm})$ was located inside the vessel containing the nanoparticles of $\mathrm{TiO}_{2}$ supported on $\mathrm{AC}$. A black lamp provided a UV light source with an intensity of 1 $\mathrm{mW} / \mathrm{cm}^{2}$ (Sankyo Denki FL 20SBLB, main peak located at $352 \mathrm{~nm}$ ). NO $\mathrm{NO}_{\mathrm{x}}$ degradation was carried out at room temperature using an air stream containing 1.0 ppm NO as the feedstock. Two mass flow controllers (MFCs) (type MFC-CB control box, Fluka, USA) manipulated the relative humidity $(\mathrm{RH}$ $=50 \%$ ) in the feeding stream. The reaction gas in the feeding stream passed through a vessel containing $\mathrm{TiO}_{2}$ supported on $\mathrm{AC}(0.2 \mathrm{~g})$ at a flow rate of $1 \mathrm{~L} / \mathrm{min}$. The measurements of $\mathrm{NO}$ and $\mathrm{NO}_{x}$ concentrations were performed using an on-line chemiluminescence analyzer (AC32M, Environnement SA, France) with a detection limit of $0.4 \mathrm{ppb}$ and a continuous sampling rate of $0.7 \mathrm{~L} /$ min. $\mathrm{NO}$ and $\mathrm{NO}_{x}$ concentrations were measured in successive 5-s steps. The $\mathrm{NO}_{2}$ concentration was obtained from the difference between the $\mathrm{NO}_{\mathrm{x}}$ and NO concentrations ${ }^{12,36}$.

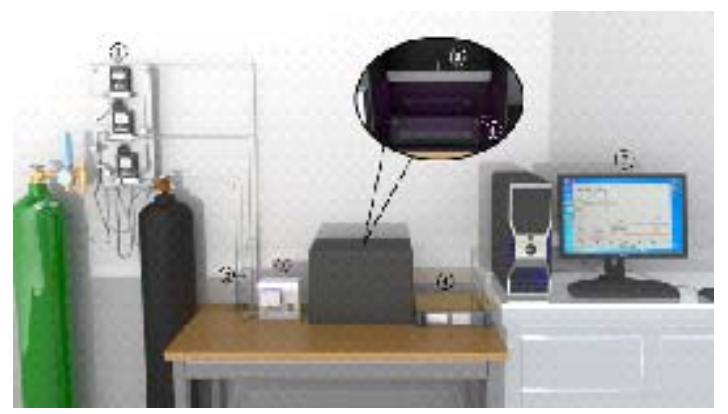

Fig. 1: Schematic diagram of the continuous flow reaction system for the photocatalytic degradation of NO: 1. Mass flow controler 2.Tramp 3. Peristaltic pump 4.

Chemiluminescence equipment 5 . UV source 6.Reactor 7. Computer

\section{RESULTS}

Specific surface area and pore structural characterization analysis of the activated carbon The $\mathrm{N}_{2}$ adsorption isotherms at $77 \mathrm{~K}$ of both the untreated sample (AC without titanium oxide) and samples coated with titanium oxide are shown in Fig. 2. The adsorption isotherms of the activated 
carbons exhibited a hybrid I/IV isotherm according to the IUPAC classification, which is characteristic of microporous materials with an important contribution of mesoporosity ${ }^{37}$. The $\mathrm{N}_{2}$ adsorption isotherms also showed a hysteresis loop (type $\mathrm{H} 4$ ) at relative pressures about 0.5 where the adsorption and desorption branches were parallel; this indicates the presence of small slit-shaped pores and well-developed mesoporosity for all the catalysts $^{37}$. Isotherm data were analyzed for BET area, total pore volume, micropore volume and average pore width. Specific surface areas were calculated according to the BET method. Total pore volumes were directly derived from the adsorbed quantity at high relative pressures $\left(P / P^{\circ} 0.95\right.$, where $\mathrm{P} \circ$ is the saturation pressure of nitrogen at $77.36 \mathrm{~K}$ and equals $101.38 \mathrm{kPa}$ ). The results obtained from the nitrogen isotherms are presented in Table 1. Adsorption data were analyzed by the NLDFT equilibrium model for slit pores and the pore size distributions (PSD) were calculated ${ }^{38}$. The PSD, i.e. the distribution of pore volume with respect to pore size, is represented by the derivative of $d V / d r$ as a function of $r$, where $V$ is the pore volume and $r$ is the pore radius. In the case of carbons, in which the pores are considered to be mostly slit-shaped, pore width (w) can replace pore radius ( $r$ ), and the PSD can be presented similarly by the derivative of $d V /$ $d w$ as a function of $w$ (results not shown).

When the $A C$ was coated with titanium oxide using the CVD and sol-gel methods, the porous structure was modified. This change in the

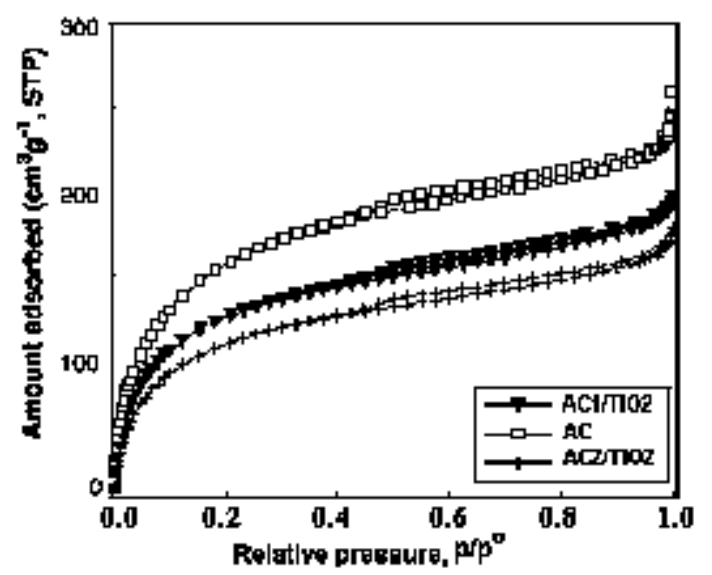

Fig. 2: $\mathrm{N}_{2}$ adsorption isotherms at $77 \mathrm{~K}$ for the activated carbons prepared from orange peel ( $\mathrm{AC}, \mathrm{AC} 1 / \mathrm{TiO}_{2}$ and $\mathrm{AC} 2 / \mathrm{TiO}_{2}$ ) textural structure was most noticeable in the AC2/ $\mathrm{TiO}_{2}$ sample. This can be explained considering that, in this catalyst, particles may plug some of the pores, whereas the AC covered using the CVD method had a greater number of particles in the pores because a $\mathrm{TiO}_{2}$ vapor was generated. This type of change was observed in the values of the apparent BET area and PSD. These results are consistent, and it was found that the pore size was smaller for $\mathrm{AC} 2 / \mathrm{TiO}_{2}$, as suggested in the previous paragraph.

\section{XRD analysis}

The materials were analyzed by XRD and the results are shown in Fig. 3. The diffraction patterns of pure $\mathrm{TiO}_{2}, \mathrm{AC}$ alone, $\mathrm{AC} 1 / \mathrm{TiO}_{2}$, and $\mathrm{AC} 2 /$ $\mathrm{TiO}_{2}$ are presented for comparison. The two broad peaks of the AC prepared from orange peel sample indicate that the content of the well-ordered crystalline phase can be neglected. The peak from $20^{\circ}$ to $30^{\circ} 2$, corresponds to reflexes in the (002) plane, whereas the peak from $40^{\circ}$ to $48^{\circ} 2$, corresponds to the (100) plane ${ }^{39-42}$. The pattern exhibits broad peaks and the absence of a sharp peak indicating a predominantly amorphous structure, which is a typical characteristic of AC. This also indicates an advantageous property for welldefined adsorbents.

The photocatalysts were dominated mainly by the anatase phase. The main diffraction peaks at $25.3^{\circ}, 37.8^{\circ}, 48^{\circ}, 53.9^{\circ}, 55^{\circ}$ and $62.5^{\circ} 2$, were assigned to the diffraction planes of (1 01$)$, (0 0 4), (2 0 0), (1 0 5), (2 11 1) and (2 04 4) for anatase (JCPDS \# 021-1272), respectively. Other crystal phases corresponding to peaks at 27.4 and $36.1^{\circ}$ 2 , were assigned the diffraction peaks of $\left(\begin{array}{lll}1 & 1 & 0\end{array}\right)$ and (1 $\left.\begin{array}{lll}0 & 1\end{array}\right)$ of the rutile phase (JCPDS \# 021-1276), respectively. The XRD patterns revealed the diffraction peaks of a mixture of the anatase and rutile phases, which is favorable for photocatalytic reactions ${ }^{43-49}$. XRD also showed that the AC prepared in this study did not affect the crystal structure of $\mathrm{TiO}_{2}$ when it was deposited on $\mathrm{AC}$ by the CVD method, but the peak intensity was lower and the peaks were wider, while the peaks in the $\mathrm{AC} 2 / \mathrm{TiO}_{2}$ samples decreased and some cases were barely visible. This clearly shows the influence of the method used to coat AC with titanium oxide. Data analysis of the XRD patterns was performed 
using the PowderX program. The crystallite or grain size $\left(d_{\mathrm{XRD}}\right)$ was determined using the Scherrer formula. The anatase (compound principal registered) crystallite sizes of $\mathrm{AC} 1 / \mathrm{TiO}_{2}$ and $\mathrm{AC} 2 /$ $\mathrm{TiO}_{2}$ were 3.4 and $4.5 \mathrm{~nm}$, respectively. The diffraction peak width increased with increasing BET surface area and pore volume, as shown above. Therefore, the crystal size of $\mathrm{TiO}_{2}$ decreased according to Eq. (1). This is in agreement with the literature on nanostructured powders with high purity ${ }^{44-49}$. The method used to coat $\mathrm{AC}$ with $\mathrm{TiO}_{2}$ may be responsible for this reduction in crystallite size, because the formation of $\mathrm{TiO}_{2}$ in the CVD method, which is performed in the vapor phase, allows free particles to enter the pores of $A C$, while the sol-gel method produces small agglomerations of particles with a slightly larger size.

This suggests that $A C$ could enhance the photocatalytic activity of $\mathrm{NO}_{x}$ and would be presented in composited samples in this case with $\mathrm{TiO}_{2}$. Furthermore, in additional calculations, the anatase content $\left(f_{(A)}\right)$ was determined from the integrated intensity of the anatase diffraction line (1 $\left.0 \begin{array}{ll}1 & 0\end{array}\right), I A$, and that of the rutile diffraction line (1 1 $0)$, IR, using the following equation (Eq. 2) ${ }^{46}$.

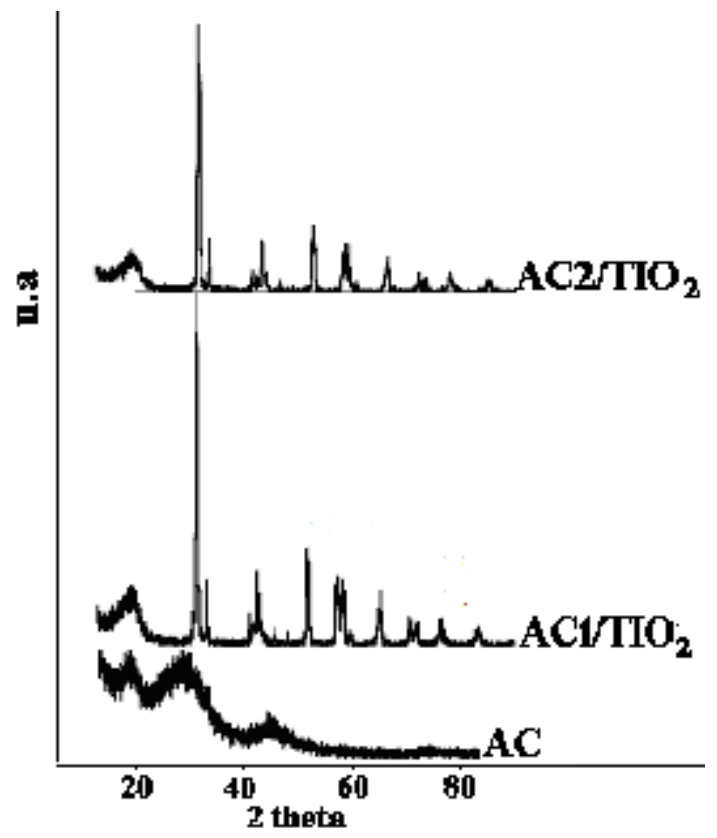

Fig. 3: XRD patterns of the prepared samples

$$
f_{(A)}=\frac{1}{1+12.6 \frac{I_{A}}{I_{R}}}
$$

The anatase content of $\mathrm{AC}_{1} / \mathrm{TiO}_{2}$ and $\mathrm{AC2} /$ $\mathrm{TiO}_{2}$ was 0.977 and 0.898 , respectively. The $f_{(A)}$ values show that the phases of the obtained catalysts were mainly anatase with a small amount of rutile.

\section{TEM analysis}

Fig. 4 shows TEM images of the $\mathrm{AC} 1 / \mathrm{TiO}_{2}$ and $\mathrm{AC} 2 / \mathrm{TiO}_{2}$ samples. The samples clearly present a microstructure consisting of $\mathrm{TiO}_{2}$ nanoparticles (H"3 nm) homogeneously dispersed on $\mathrm{AC}$, especially in the case of $\mathrm{AC} 1 / \mathrm{TiO}_{2}$. After coating, the titanium oxide nanoparticles remain homogeneously dispersed around the porous structure of AC (Fig. 4a).

The $\mathrm{AC} 1 / \mathrm{TiO}_{2}$ sample (Fig. 4a) showed $\mathrm{TiO}_{2}$ nanoparticles embedded on a mass of $A C$ obtained from orange peel. The image indicates that there were effective interactions between the oxide and the chemical groups on the carbon, as result of the more efficient CVD preparation method developed in this work. This corroborates the XRD results, which indicated that $\mathrm{TiO}_{2}$ particles penetrated the more porous structure of $A C$ when the CVD method was used. Fig. 4b show a TEM image of the $\mathrm{AC} 2 / \mathrm{TiO}_{2}$ sample, with accumulation of quite visible particles, unlike those obtained by the CVD method.

\section{$\mathrm{NO}_{x}$ degradation results}

Before starting the photocatalytic experiment, we performed several preliminary studies to optimize several variables such gas flow, temperature and other variables for the catalytic test of the photoactivity of the $\mathrm{AC}_{1} / \mathrm{TiO}_{2}$ and $\mathrm{AC} 2 /$ $\mathrm{TiO}_{2}$ systems in the $\mathrm{NO}_{x}$ degradation reaction, as described in the Experimental section. The NO and $\mathrm{NO}_{2}$ concentrations were monitored continuously, and a profile of the concentrations as a function time was recorded (see Fig. 5 for a representative plot). As expected, the pure AC pure was catalytically inactive in the reaction, while the $A C 1 /$ $\mathrm{TiO}_{2}$ and $\mathrm{AC} 2 / \mathrm{TiO}_{2}$ catalysts were active under our experimental conditions and showed good 


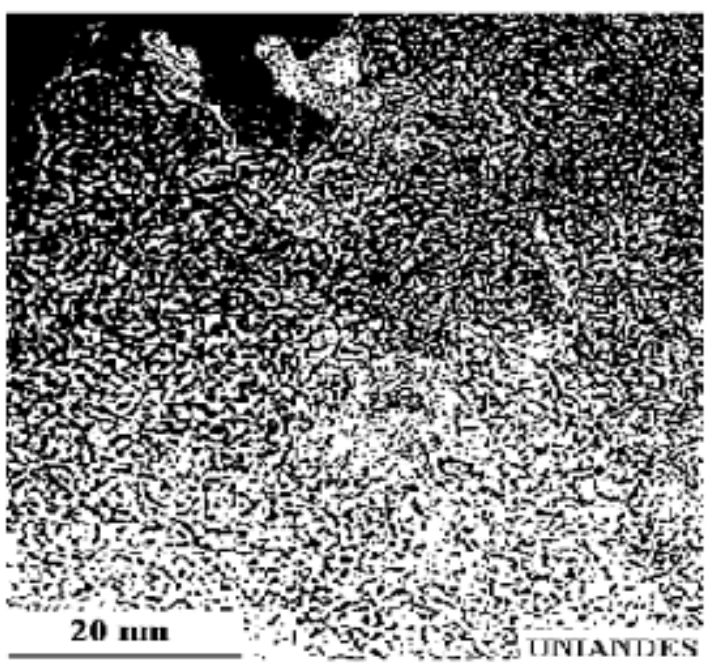

Fig. 4: TEM photographs of (a) $\mathrm{AC} 1 / \mathrm{TiO}_{2}$ and (b) $\mathrm{AC} 2 / \mathrm{TiO}_{2}$

conversion values. As shown in Fig. 5, the NO concentration reached a minimum value followed by a slow and continuous deactivation process after the adsorption of $\mathrm{NO}_{3}^{-}$on the catalytic active sites. Simple adsorption and desorption of NO gas (not due to photocatalysis) by the catalysts $\left(\mathrm{AC} 1 / \mathrm{TiO}_{2}\right.$ and $\mathrm{AC} 2 / \mathrm{TiO}_{2}$ ) occurred in the dark (Fig. 5(a) and (b)). The net removal of $\mathrm{NO}$ gas at the beginning of illumination for $\mathrm{AC} 1 / \mathrm{TiO}_{2}$ was higher in comparison to $\mathrm{AC} 2 / \mathrm{TiO}_{2}$ The results show that the conversion values were associated with the $\mathrm{TiO}_{2}$ coating method, since the catalytic activity of $\mathrm{AC} 1 / \mathrm{TiO}_{2}$ was greater than that of $\mathrm{AC} 2 / \mathrm{TiO}_{2}$; this was associated with the findings described earlier. The sample obtained by the CVD method had higher catalytic activity, which shows that the deposited vapor phase $\mathrm{TiO}_{2}$ was more efficient than $\mathrm{TiO}_{2}$ deposition by the sol-gel method where the pores of the AC were blocked. The CVD method allows for the uniform deposition of $\mathrm{TiO}_{2}$ nanoparticles within the porous

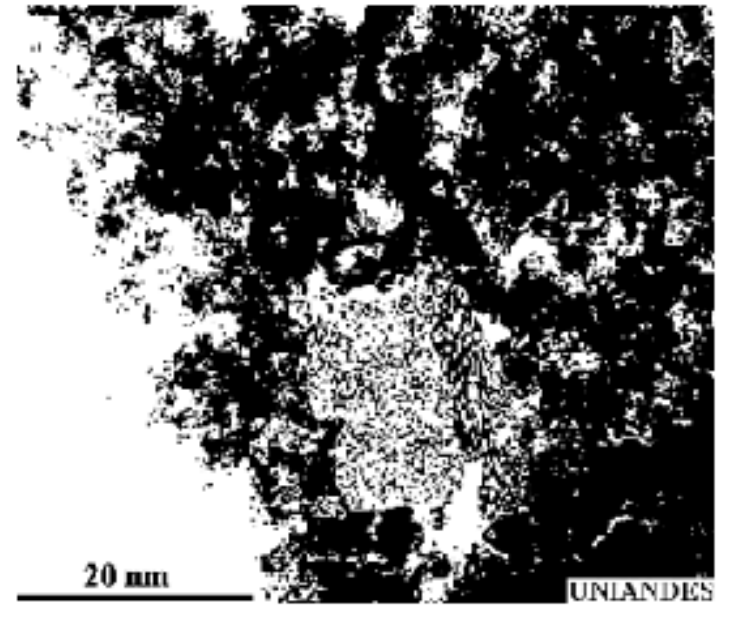

structure, which generates a more active sample. Fig. 5 shows the typical evolution of the $\mathrm{NO}, \mathrm{NO}_{x}$ and $\mathrm{NO}_{2}$ concentrations during a test intended to assess the photocatalytic efficiency of the coating. The degradation of nitrogen oxides by photocatalysis led to the oxidation of $\mathrm{NO}$ to $\mathrm{NO}_{2}$, which, in turn, produced nitrite and nitrate ions (reaction (4)).

The mechanism of the photocatalytic reaction using supported nanoparticles of titanium, in this case AC prepared from orange peel, has been studied by several authors and is published in the literature ${ }^{50,51}$. Several studies agree on a number of steps that we reproduced in our research, considering that these reactions are very consistent with what we have established in this investigation. Thus, we believe that the photocatalytic process occurs in three main steps: (1) mass transport and adsorption of pollutants from the bulk air to the

Table 1 : Structural parameters calculated from nitrogen adsorption isotherms at $77 \mathrm{~K}$ for the samples prepared in this research

\begin{tabular}{lccccc} 
Sample & $\mathrm{S}_{\mathrm{BET}}\left[\mathrm{m}^{2} \cdot \mathbf{g}^{-1}\right]$ & $\mathrm{V}_{\text {TOTAL }}\left[\mathrm{Cm}^{3} \cdot \mathbf{g}^{-1}\right]$ & $\mathrm{V}_{\text {MICRO }}\left[\mathrm{cm}^{3} \cdot \mathbf{g}^{-1}\right]^{\mathrm{a}}$ & $\mathrm{V}_{\text {MESO }}\left[\mathrm{cm}^{3} \cdot \mathbf{g}^{-1}\right]^{\mathrm{b}}$ & $\mathbf{W}_{\mathrm{o}}, \mathbf{N}_{2}(\mathrm{DR})\left[\mathrm{cm}^{3} \cdot \mathbf{g}^{-1}\right]$ \\
\hline $\mathrm{AC}$ & 625 & 0.55 & 0.33 & 0.12 & 0.32 \\
$\mathrm{AC} / \mathrm{TiO}_{2}$ & 580 & 0.50 & 0.30 & 0.10 & 0.28 \\
$\mathrm{AC}_{2} / \mathrm{TiO}_{2}$ & 500 & 0.45 & 0.26 & 0.07 & 0.24 \\
\hline
\end{tabular}

a Evaluated at $\mathrm{P} / \mathrm{P}^{\circ} \mathrm{H} \sim 0.95$. ${ }^{\text {b }}$ Evaluated from DFT applied to $\mathrm{N}_{2}$ adsorption data. 
surface of the catalyst; (2) photocatalytic reaction on the catalyst; (3) desorption and mass transport of the reaction products from the surface of the catalyst to the air. The photocatalytic oxidation mechanism has been investigated extensively ${ }^{51-55}$. Based on previous publications ${ }^{50,51}$ and the results of the present study, we believe that Eqs. (3)-(12) represent the photocatalytic reaction mechanism of NO. Eq. (3) shows the photon-mediated generation of electron/hole pairs ${ }^{50-52}$.

$\mathrm{TiO}_{2}+\mathrm{h} \mu \rightarrow \| \mathrm{e}^{+}+\mathrm{h}^{-}$

Eqs. (2)-(4) show the adsorption of the reactants onto the photocatalyst:

$$
\begin{aligned}
& \mathrm{TiO}_{2}+\mathrm{H}_{2} \mathrm{O} \rightarrow \mathrm{TiO}_{2}-\mathrm{H}_{2} \mathrm{O} \\
& \mathrm{TiO}_{2}+\mathrm{O}_{2} \rightarrow \mathrm{TiO}_{2}-\mathrm{O}_{2} \\
& \mathrm{TiO}_{2}+\mathrm{NO} \rightarrow \mathrm{TiO}_{2}-\mathrm{NO}
\end{aligned}
$$

Eq.(5) shows the recombination of the generated electron and hole pairs:

$$
\mathrm{e}^{-}+\mathrm{h}^{+} \rightarrow \text { heat }
$$

Eq.(5) and (7) show the trapping of the generated holes and electrons:

$$
\begin{aligned}
& \mathrm{h}++\mathrm{H}_{2} \mathrm{O} \rightarrow \mathrm{OH}^{-}+\mathrm{H}^{+} \\
& \mathrm{e}^{-}+\mathrm{O}_{2} \rightarrow \mathrm{O}_{2}^{-}
\end{aligned}
$$

Eqs.(8)-(10) show the oxidation of NO:

$$
\begin{aligned}
& \mathrm{NO}+\mathrm{OH}^{-} \rightarrow \mathrm{HNO}_{2} \\
& \mathrm{HNO}_{2}+\mathrm{OH}^{-} \rightarrow \mathrm{NO}_{2}+\mathrm{H}_{2} \mathrm{O} \\
& \mathrm{NO}_{2}+\mathrm{OH}^{-} \rightarrow \mathrm{NO}_{3}^{-}+\mathrm{H}^{+}
\end{aligned}
$$

These reactions clearly show the role of adsorbed oxygen and water and its very important role in the heterogeneous photocatalytic oxidation reaction. Oxygen is used to trap the generated electrons on the $\mathrm{TiO}_{2}$ surface coating on AC. Hydroxyl radicals are produced from water by trapping the generated holes on the $\mathrm{TiO}_{2}$ surface, which then leads to the oxidation of $\mathrm{NO}_{2}$ and finally $\mathrm{NO}_{3}{ }_{3}^{-}$. In another series of studies reported in the literature, these reactions clearly show the role of oxygen and water ${ }^{56}$.

The photocatalytic oxidation reaction takes place immediately when the sample is exposed to the visible light. The $\mathrm{NO}_{2}$ concentration increases and quickly reaches a stable condition. After reaching the maximum degradation rate, the process will slightly slow down and reach a stable conversion condition. Fig. 3 shows the concentration change in NOx during the photocatalytic oxidation reaction. The photocatalytic oxidation of $\mathrm{NO}$ is calculated from Eq. (13):

$\mathrm{NO}_{\text {con }}(\%)=\left[\mathrm{C}_{\text {con }}\right]_{\text {in }}-\left[\mathrm{C}_{\mathrm{NO}}\right]_{\text {out }} /\left[\mathrm{C}_{\mathrm{NO}}\right]_{\text {in }} 100$

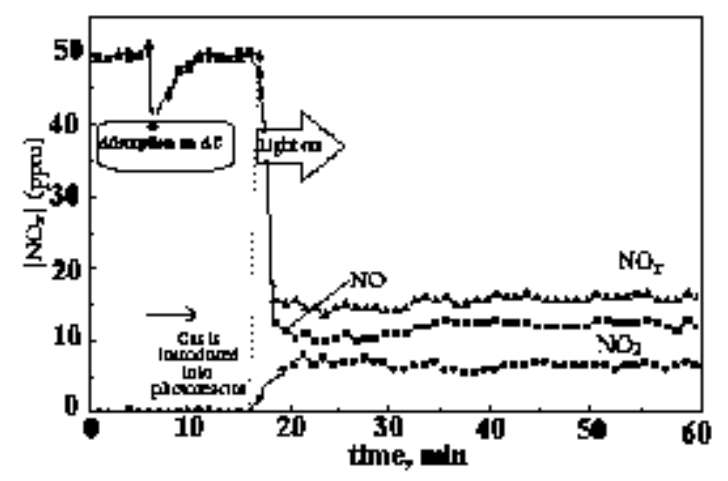

(a) $\mathrm{AC} 1 / \mathrm{TiO}_{2}$

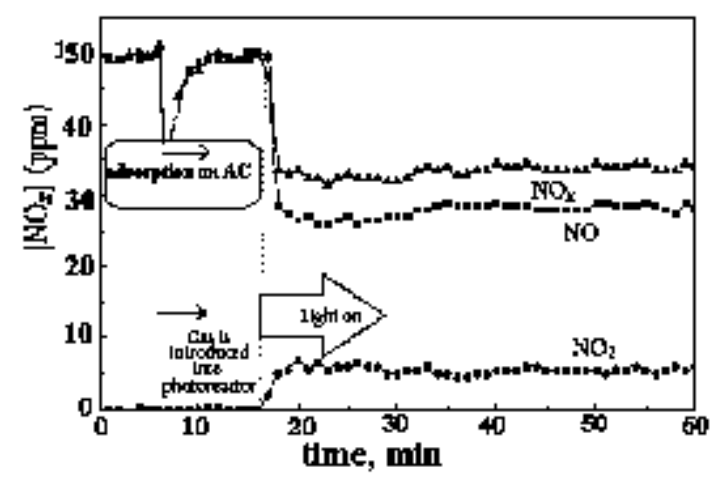

(b) $\mathrm{AC2} / \mathrm{TiO}_{2}$

Fig. 5: Profiles of variation in the $\mathrm{NO}_{\mathrm{x}}$ concentration in the reactor during a typical test 
where $\left[\mathrm{C}_{\mathrm{NO}}\right]_{\text {out }}$ is defined as the average NO concentration of the last $5 \mathrm{~min}$ in the measurement time. Eq. (11) shows the formation of $\mathrm{NO}_{2}$ during the oxidation reaction. However, not all the produced $\mathrm{NO}_{2}$ can be oxidized to $\mathrm{HNO}_{3}$ because a small part of it is released into the air due to desorption. So, the exit pollutant is composed of the remaining $\mathrm{NO}$ and the undesired intermediate $\mathrm{NO}_{2}$. The amount of $\mathrm{NO}_{\mathrm{x}}$ removed is calculated using $\mathrm{Eq}$. (14):

$$
\mathrm{NO}_{\text {xcon }}(\%)=\left[\mathrm{C}_{\mathrm{NOx}}\right]_{\text {in }}-\left[\mathrm{C}_{\mathrm{NOx}}\right]_{\text {out }} /\left[\mathrm{C}_{\mathrm{NOx}}\right]_{\text {in }} 100
$$

where $\left[\mathrm{C}_{\mathrm{NOx}}\right]_{\text {out }}$ is defined as the average $\mathrm{NO}_{x}$ concentration at the exit port in the last $5 \mathrm{~min}$ of the measurement time.

\section{CONCLUSIONS}

In this study, two catalysts $\left(\mathrm{AC} 1 / \mathrm{TiO}_{2}\right.$ and $\mathrm{AC} 2 / \mathrm{TiO}_{2}$ ) were prepared using $\mathrm{AC}$ derived from orange peel by two different methods to achieve the deposition of titanium oxide nanoparticles (CVD and sol-gel). The results show the superiority of the $\mathrm{AC} 1 / \mathrm{TiO}_{2}$ catalyst, prepared using the CVD method to apply $\mathrm{TiO}_{2}$ nanoparticles onto the surface of the $A C$, because this method allows vaporized nanoparticles to enter into the porous structure. The $X R D$ results show that the nanoparticles were a mixture of the anatase and rutile phases, which makes the catalyst more efficient regarding $\mathrm{NO}_{x}$ degradation. $\mathrm{NO}_{\mathrm{x}}$ degradation assays were used to test catalyst efficiency.

\section{ACKNOWLEDGMENTS}

The authors wish to thank the framework agreement between the Universidad Nacional de Colombia and the Universidad de los Andes (Colombia) under which this research was carried out. Additionally, the authors thank the Faculty of Sciences and the Vice-Rector of Research of the Universidad de los Andes (Bogotá, Colombia) for funding this research.

\section{REFERENCES}

1. Ao, C.H.; Lee, S.C.; Mak, C.L.; Chan, L.Y. Appl. Catal. B, 2003, 42,119-129

2. Haywood, J.M.; Cooper, C.D. J. Air Waste Manage. Assoc. 1998, 48, 238-246

3. Adewuyi, Y.G.; Owusu, S.O. Ind. Eng. Chem. Res. 2003, 42, 4084-4100

4. Farrell, A. Energy Policy, 2001,29,1061-1072

5. Sekiguchi, K.; Saito, M.; Lee.Y.; Kim, Y.; Sakamoto, K. Chem. Eng. J. 2006, 118, 127130

6. Castro, T.; Madronich, S.; Rivale, S.; Muhlia, A.; Mar, B. Atmos. Environ. 2001, 35, 17651772

7. Mok, Y.S. Chem. Eng. J. 2006, 118, 63-67

8. Zamansky, V.M.; Ho, L.; Maly, P.M.; Seeker, W.R. Combust. Sci. Technol. 1996, 120, 255272

9. Ibusuki, T.; Takeuchi, K. J. Mol. Catal. 1994, 88, 93-102 (1994).

10. Wu, Z.; Sheng, Z.; Liu, Y.; Mo, H.W.J. J. of Hazardous Mat. 2011, 185, 1053-1058

11. Monge, M.e.; D’Anna, B.; George, C. Phys. Chem. Chem. Phys. 2010, 12 (31), 8991-8998
12. Ballari, M.M.; Hunger, M.; Husken, G.; Brouwers, H.J.H. Appl. Catal. B: Env. 2010, 95, 245-254

13. Puma, G.L.; Bono, A.; Krishnaiah, D.; Collin, J.G. J. of Haz. Mat. 2008, 157, 209-219

14. Matos, J.; Laine, J.; Hermann, J. Appl. Catal. B: Environ. 1998, 18 (3-4), 281-291

15. Herrmann, J.; Matos, J.; Disdier, J.; Guillard, C.; Laine, J.; Malato, S.; Blanco, J. Catal. Today. 1999, 54 (2-3); 255-265 (1999).

16. Hu, Z.; Vansant, E.F. Microp. and Mesop. Mater. 1995, 3(6), 603-612

17. Arriagada, R.; Garcia, R.; Molina-Sabio, M., Rodriguez-Reinoso, F., Microp. and Mesop. Mater. 1997, 8(3-4), 123-130

18. Arana, J.; Dona-Rodriguez, J.M.; Rendon, E.T.; Cabo, C.G.; Gonzalez-Diaz, O.; HerreraMelian, J.A.; Perez-Peña, J.; Colon, G.; Navio, J.A. Appl. Catal. B. 2003, 44(2), 161-172

19. Moreno-Piraján, J.C.; Giraldo, L. E-Journal of Chemistry. 2012, 9(2), 926-937

20. Keith, K. H.; McKay, G. J. Hazard Mater. 2008, 160, 845-854 
21. Purevsuren, B.; Avid, B.; Narangerel, J.; Gerelmaa, T.; Davaajav, Y. J. Mater. Sci. 2004, 9(2), 737-740

22. Hsisheng. T.; Hsieh, C.T. Ind. Eng. Chem. Res. 1998, 37(9), 3618-3624

23. Suárez-García, F.; Martínez-Alonso, A.; Tascón, J.M.D. Carbon. 2001, 39, 1111-1115

24. Molina-Sabio, M.; Rodríguez-Reinoso, F.; Caturla, F.; Sellés, J.M. Carbon, 1995, 33, 1105-1113

25. Baquero M C, Giraldo L, Moreno J.C, Suárez-García F, Martínez-Alonso, A. Tascón, J.M.D. J Therm Anal Appl Pyrol. 2003, 70, 779-784

26. Moreno-Piraján, J.C.; Giraldo, L., J. Anal Appl Pyrol. 2010, 87(2), 288-290

27. Moreno-Piraján, J.C.; Giraldo, L. J. Anal Appl Pyrol. 2010, 87(2), 188-193

28. Ding, Z.; Hu, X.; Yue, P.; Lu, G.; Greenfield, P. Cat.Today. 2001, 68, 173-182

29. Amjad, H.; El-Sheikh, A. P.; Newman, H.A.D.; Suki, P.; Neil, C.; Steven, Y. Surf. \& Coat. Tech. 2004, 187, 284- 292

30. Slimena, H.; Houasa, A.; Nogierb, J.P. J. of Phot.y and Photobio. A: Chem. 2001, 221, 13-21

31. Stoeckli, F.; Centeno, T.A.; Donnet, J.B.; Pusset, N.; Papirer, E. Fuel. 1995, 74, 158288

32. Nakagawa, Y.; Molina-Sabio, M.; RodríguezReinoso, F. Micropor. Mesopor. Mat, 2007, 103, 29-34

33. Yorgun, S.; Vural, N.; Demiral, H. Micropor. Mesopor. Mater. 2009, 122, 189-194

34. Vargas-Delgadillo, D.; Giraldo, L.; MorenoPiraján, J.C. E-Journal. Chem. 2010, 7, 531 539

35. Hirano, M.; Nakahara, C.; Ota, K.; Tanaike, O.; Inagaki, M. J. Solid State Chem. 2003, 170, 39-47

36. Dalton, J.S.; Janes, P.A.; Jones, N.G.; Nicholson, J.A.; Hallam, K.R.; Allen, G.C. Env. Poll. 2002, 120, 415-422

37. Sing, K.S.W.; Everett, D.H.; Haul, R.A.W.; Moscou, L.; Pierotti, R.A.; Rouquerol, J.; Siemieniewska, T. Pure and Applied
Chemistry. 1985, 57, 603-619

38. Landers, J.; Gor, G.Y.; Neimark, A.V. Colloids and Surfaces A: Physicochem. Eng. Aspects. 2013, 437, 3-32

39. Linh, L.L.T.; Chin, S.; Ju, J.; Anh, H. Powder Technology. 2012, 225,167-175

40. Yoon, K.H.; Noh, J.S.; Kwon, C.H.; Muhammed, M. Mat. Chem. and Phys. 2006, 95, 79-83

41. Kumar, K.; Saxena, R.K.; Kothari, R.D.; Suri, K.; Kaushik, N.K.; Bohra, J.N. Carbon. 1997, 35(12), 1842-1844

42. Hashemian, S.; Zahra, K.; Yazdi, A. J. Ind. and Eng. Chem., 2014, 20, 1892-1900

43. Vasilyeva, E.; Tolochko, O.; Kim, B.; Lee, D.; Kim, D. Microelec. Jour. 2009, 40, 687-691

44. Kim, J.; Kim, B. Scripta Materialia 2004, 50, 969-972

45. Wang, Z.; Choi, C.; Kim, J.; Kim, B.; Zhang, Z. Materials Letters 2003, 57, 3560-3564

46. Toyoda, M.; Nanbu, Y.; Nakazawa, Y.; Hirano, M.; Inagaki, M. App. Cat.B: Env. 2004, 49, 227-232

47. Arbuj, S.S.; Hawaldar, R.R.; Mulik, U.P.; Wani, B.N.; Amalnerkar, D.P.; Waghmode, S.B. Mat. Sci.and Eng.B. 2010,168, 90-94

48. Spurr, R.A.; Myers, H. Anal. Chem. 1957, 29, 760-762

49. Mädler, L.; Stark, W.J.; Pratsinis, S.E. J. of Mat. Res. 2002, 16, 1356-1362

50. Yu, Q.L.; Brouwers, H.J.H. App. Cat. B: Env. 2009, 92, 454-461

51. Choi, J.; Park, H.; Hoffmann, M. R. J. Mater. Res. 2010, 25,149-158

52. Devahasdin, S.; Fan, C.; Li, J.K.; Chen, D.H. J. Photochem. Photobiol. A: Chem. 2003, 156; 161-170

53. Wang, H.; Wu, Z.; Zhao, W.; Guan, B. Chemosphere. 2007, 66, 185-190

54. Zhang, J.; Hu, Y.; Matsuoka, M.; Yamashita, H.; Minagawa, M.; Hidaka, H.; Anpo, M. J. Phys. Chem. B. 2001, 105, 8395-8398

55. Turchi, C.S. ; Ollis, D.F. J. Catal. 1990, 122; 178-192

56. Lim, T.H.; Jeong, S.M.; Kim, S.D.; Gyenis, J. J. Photochem. Photobiol. A: Chem. 2000, 134, 209-217. 